\title{
Revisiting the Environmental Kuznets Curve Hypothesis in a Tourism Development Context
}

\author{
GLAUCO DE VITA ${ }^{1}$, SALIH KARTIRCIOGLU ${ }^{2}$, LEVENT ALTINAY $^{3}$, SAMI \\ FETHI $^{4}$ AND MEHMET MERCAN ${ }^{5}$
}

\author{
1 and 3 Faculty of Business, Oxford Brookes University, Oxford, UK \\ 2 and 4 Eastern Mediterranean University, North Cyprus, Turkey \\ 5 Hakkari and Adnan Menderes University, Turkey
}

Cite as: De Vita G., Karticioglu S., Altinay L, Fethi S and Mercan M. (2015)

'Revisiting the Environmental Kuznets Curve Hypothesis in a Tourism Development Context', Environmental Science and Pollution Research (Impact Factor: 2.76), in press, 12/2015; DOI: 10.1007/s11356-015-4861-4 


\title{
Revisiting the Environmental Kuznets Curve Hypothesis in a Tourism Development Context
}

\begin{abstract}
This study investigates empirically an extended version of the Environmental Kuznets Curve model that controls for tourism development. We find that international tourist arrivals into Turkey alongside income, squared income and energy consumption, cointegrate with $\mathrm{CO} 2$ emissions. Tourist arrivals, growth and energy consumption exert a positive and significant impact on $\mathrm{CO} 2$ emissions in the long-run. Our results provide empirical support to EKC hypothesis showing that at exponential levels of growth, $\mathrm{CO} 2$ emissions decline. The findings suggest that despite the environmental degradation stemming from tourism development, policies aimed at environmental protection should not be pursued at the expense of tourism-led growth.
\end{abstract}

Key Words: Tourism development; $\mathrm{CO}_{2}$ emissions; environmental Kuznets curve; Turkey

\section{INTRODUCTION}

The interactions between energy consumption, economic growth and environmental pollution have already been investigated extensively in the energy literature. However, less attention has been paid to this relationship with respect to particular sectors of the economy and, most notably, the tourism industry. This is particularly striking when considering that for advanced and diversified economies the contribution of tourism to 
GDP ranges from about 2\% to over 10\% (UNWTO, 2009) and for many small developing countries and islands 'tourism is the single most important sector of the economy' (Adamou and Clerides, 2009, p. 3).

The role of the tourism industry for stimulating economic development is, of course, fairly intuitive, and several studies have confirmed tourism development as an engine of economic growth in some countries (for example, Katircioglu 2009, found this to be the case for Turkey). Indeed, cross-country evidence in support of the tourism-led growth hypothesis abounds. Whilst it is also self-evident that tourism development leads to a growth in energy use, the expansion of the tourism industry, via investments, tourist arrivals, and tourism-related economic activities, can also be expected to lead to an increase in the level of pollution.

Indeed, tourism development activities come with an increased demand for energy for various functions such as transportation, catering, accommodation, water supply, and the management of tourist attractions (Gössling, 2002). The higher use of energy for building and maintaining tourism infrastructure, in turn, can be expected to cause various forms of environmental and/or ecological degradation (Lee and Brahmasrene, 2013).

Given the above, an investigation of the relationship between inbound tourism and carbon dioxide $\left(\mathrm{CO}_{2}\right)$ emissions which, contextually, takes into account the wider role of energy consumption and economic growth on environmental degradation, should be of great interest to increase our understanding of these intricate relationships. The findings should also be of considerable value to policy makers, particularly in countries which, like Turkey, are faced by the dichotomous policy dilemma of stimulating economic development via tourism-led growth (see High Planning Commission, 2007) 
whilst ensuring improvements in environmental protection, which Turkey is expected to undertake en route to EU accession (Republic of Turkey Ministry of Foreign Affairs, 2013).

The impact of energy consumption and economic growth on environmental pollution has already been subjected to considerable empirical scrutiny in the energy literature (Ang, 2008; Soytas and Sari, 2008; Zhang and Cheng, 2009; Ozturk and Acaravci, 2010). These studies generally support the existence of a positive effect of energy use and economic growth on $\mathrm{CO}_{2}$ emissions and, more generally, environmental degradation. But it is the related stream of literature that has tested the validity of the Environmental Kuznets Curve (EKC) hypothesis (Coondoo and Dinda, 2002; Dinda, 2004; Stern, 2004; Luzzati and Orsini, 2009; etc.) that has raised some controversy, with mixed evidence emerging as to whether the EKC hypothesis, which postulates an inverted U-shaped relationship between environmental degradation and income per capita, holds.

Against this backdrop, the theoretical importance and policy relevance of investigating the role that tourism development might have on $\mathrm{CO}_{2}$ emissions in the context of the EKC framework cannot be overstated. The literature focusing on the impact of tourism on $\mathrm{CO}_{2}$ emissions is not vast (Lin, 2010; Lee and Brahmasrene, 2013; Solarin, 2014; Tsai et al., 2014, etc.). However, to the best of our knowledge, no study has examined the relationship between tourism development and $\mathrm{CO}_{2}$ emissions within an EKC framework. It is this novel approach that allows us to investigate, simultaneously, the extent to which environmental pollution responds to changes in income and squared levels of income in addition to energy consumption and tourism development. 
Methodologically, another novel feature of the study lies in the use of the most recent unit root (Carrion-i-Silvestre et al., 2009) and cointegration testing techniques (Maki, 2012). These state-of-the-art techniques have the considerable advantage of permitting us to test for unit roots and cointegration whilst allowing for up to five structural breaks in the series. Another virtue of the approach that we employ lies in the adoption of the Dynamic Ordinary Least Squares (DOLS) estimation method which improves on maximum likelihood estimation procedures by providing a robust single equation approach which corrects for potential endogeneity and serially correlated errors.

Our study also makes a timely contribution to the EKC literature in the context of Turkey. Whilst several studies have already examined the relationship between $\mathrm{CO}_{2}$ emissions and growth in the context of an extended EKC framework in Turkey that includes variables such as energy consumption, foreign trade and population density (Akbostanci et al., 2009; Halicioglu, 2009; Ozturk and Acaravci, 2010), to date, no study has incorporated within such a framework a measure of tourism development.

In the next section we provide a brief review of the EKC literature and elaborate further on both the theoretical rationale of our extended EKC model and our choice of Turkey as the context of the study. The following section describes the methodology, including the models subjected to empirical testing, data used, and techniques employed. We then present and discuss the results. The final section offers a further discussion of the significance of the findings and their implications alongside profitable avenues for future research.

\section{LITERATURE REVIEW}




\section{The EKC Hypothesis}

Following the seminal contribution by Grossman and Krueger (1991), research on the validity of the EKC hypothesis has been considerable (Shafik and Bandypadhyay, 1992; Coondoo and Dinda, 2002; Dinda, 2004; Stern, 2004; Luzzati and Orsini, 2009). Grossman and Krueger (1991) were the first to point out the inverted U-shaped relationship between environmental pollutants and per capita income though it was Panayotou (1993) who later named such a relationship after the work of Kuznets (1955), who had postulated a similarly shaped relationship between income inequality and economic development.

In a nutshell, the EKC hypothesis postulates that as part of the development process, environmental degradation increases as a country's economic growth increases, but starts to decrease when income reaches the so-called 'turning point' (an unspecified income threshold after which environmental degradation can begin to recede). The hypothesis, therefore, can be seen to provide support for a policy that emphasizes economic growth (and, hence, the growth in tourism development which in many developing economies such as Turkey can act as an engine of growth) at the expense of short-term environmental protection.

If the hypothesis holds true, economic policies should allow extensive use of the environment for growth purposes. However, there are risks and dangers in pursuing such policies. If developing countries decide to overlook environmental protection by counting on rising income levels to abate the environmental damage of such a growth, detrimental consequences may accrue and cause some irreversible harm. This may take place before the predicted income threshold is met. The other danger, of course, is that the EKC 
hypothesis could be incorrect. Hence, relying on its predictions would lead to consistently inadequate environmental protection. On the other hand, relying on the assumption that the EKC hypothesis is wrong, may mean that developing countries pursuing policies of environmental protection - by doing so at the expense of economic growth - may never reach the income level (threshold) that would warrant the abating of the environmental damage they are seeking to reduce. This means that they would never allow themselves to 'grow out of environmental problems' (Shafik and Bandyopadhyay, 1992, p. 6) since 'faster growth could serve as part of the solution to the [...] emissions dilemma' (HoltzEakin and Selden, 1992, p. 3).

As elegantly explained by Grossman and Krueger (1991), and Dinda (2004), the mechanism through which economic growth affects environmental quality in the longterm is threefold; being driven by a scale effect, a composition effect and a technique effect. The scale effect occurs as pollution increases with the size of the economy. The composition effect relates to a shift in the production structure of an economy (from mainly agrarian to industrial and service-based development) which inevitably carries a re-allocation of resources. As a result, in the early stages of this development process, pollution rises as the economy's structure changes from agriculture to more resource intensive industries to fuel the expansion of the industrial and service sectors. Finally, the technique effect accounts for technological enhancements in production techniques (including cleaner technologies), leading to a reduction in pollution.

Empirical evidence on the EKC hypothesis is anything but convergent. While some studies find a linear relationship between environmental degradation and economic growth (Shafik and Bandyopadhyay, 1992, Akbostanci et al., 2009), others have provided 
evidence in support of an inverted U-shaped relationship in line with the EKC prediction (Lindmark, 2002) though discrepancies have emerged in terms of the exact 'turning point'. The benchmark study in this literature remains that by List and Gallet (1999) who showed that over the period 1929-1994, in the US, an inverted-U shaped EKC characterized the relationship between per capita emissions and per capita income at state level. Other studies still, have found an 'N-shaped relationship' (see, for example, Friedl and Getzner, 2003) which suggests that any decline of environmental degradation is only limited to the short term (He and Richard, 2010).

\section{Tourism development and the EKC hypothesis}

In an attempt to develop the EKC model beyond growth, some authors have extended the conventional EKC framework by including additional variables. Many studies have integrated the investigation of the relationship between energy consumption and output growth within the EKC framework (see, for example, Ozturk and Acaravci, 2010). Indeed, the evidence of the impact of energy use and economic growth on $\mathrm{CO}_{2}$ emissions is so overwhelming, that both of these variables are now routinely integrated into the analysis. Other variables expected to have explanatory power in the analysis of the EKC hypothesis include trade (Ang, 2008; Halicioglu, 2009) and population density (Akbostanci et al., 2009). Despite these extensions, little attention attention has been paid to the tourism sector: Katircioglu (2014a; 2014b), Katircioglu et al. (2014), Lee and Brahmasrene, 2013).

This is particularly striking when acknowledging that the inclusion of tourism in the EKC model may well affect the relative magnitude of the scale, composition and 
technique effects upon which the EKC hypothesis rests and thus help us unveil any underlying patterns that may be masked by the estimation of the sole functional relationship between income growth and environmental quality. Accounting explicitly for the role of tourism in the EKC framework, therefore, marks a noteworthy contribution to this literature. First, to establish the extent to which tourism development contributes to $\mathrm{CO}_{2}$ emissions. Second, to gauge whether despite such a direct influence on environmental degradation, further investment in tourism development could - by fuelling further economic growth - help the economy reach the exponential growth levels at which $\mathrm{CO}_{2}$ emissions would be expected to decline.

Far from being an arbitrary selection, the inclusion of tourism development within the EKC framework also finds a strong theoretical justification not only by virtue of its impact on environmental degradation as well as growth but also on the basis of the same grounds that have prompted many researchers to include a trade variable in the EKC model. This is particularly evident when it is recognized that, on a global scale, tourism has become one of the major international 'trade categories' that generate foreign exchange earnings (UNWTO, 2009). As such, tourism can be treated as any other form of trade within the theoretical extension of the EKC model. Indeed, theory suggests that environmental quality could deteriorate through the scale effect as increasing 'trade volume' (as measured by an increasing level of 'inbound tourist flows' for example) raises the size of the economy, which - in turn - increases environmental pollution. 'Trade' in the tourism industry could also be argued to lead to changes in environmental quality through the composition and/or technique effect of 'tourism trade' (as exemplified by international tourist flows). The composition effect of trade is particularly applicable to 
the consequences of tourism inflows since both the displacement hypothesis (which posits that trade openness correlates with increasing $\mathrm{CO}_{2}$ emissions) and the pollution haven hypothesis (which postulates that foreign investors are keener to relocate to developing countries with less restrictive environmental standards), appear to be relevant in the context of tourism markets, which in many developing countries are increasingly dependent upon foreign investment.

\section{The Turkish context}

Turkey has been chosen as the context for our empirical study for several reasons. First, Turkey has become a very important tourist destination market. As highlighted in the Republic of Turkey Prime Ministry tourism industry report (2010, p.6) 'The tourism industry has been one of the most important drivers behind Turkey's economic development over recent decades by reducing unemployment, raising national GDP and improving the country's balance of payments. In 2009, combined with the travel sector, the industry generated TL 95.3 billion of economic activity (approximately $10.2 \%$ of Turkey’s GDP) with an employment of approximately 1.7 million people'. Moreover, Turkey now attracts about 33.3 million tourists and it ranks $6^{\text {th }}$ in the world in attracting international tourists (World Bank, 2012).

Second, Turkey constitutes an interesting case study since it relies heavily on energy imports, which are the reason behind its persistent current account deficits over the years. At the same time, while Turkish manufacturing exports remain insufficient to compensate for current account deficits, tourism receipts have been a critical contributor to sustaining the current account (Akkemik, 2012). On the other hand, it is also tourism 
development, especially in the last two decades, that created additional demand for energy in Turkey and, in turn, this increased demand for energy led to a significant rise in $\mathrm{CO}_{2}$ emissions. Turkey's $\mathrm{CO}_{2}$ emissions without land use, land use change and forestry (LULUCF), in Gigagrams (Gg), were 141,362 in 1990. Less than two decades later, this figure had more than doubled, increasing to $297,124 \mathrm{Gg}$ by 2008 (http://emissions.findthedata.org/d/d/Turkey).

Although the latest figures (from 2008 onwards) show an initial drop in $\mathrm{CO}_{2}$ emissions for Turkey, Turkey still ranks 22nd in the league table of the world's worst $\mathrm{CO}_{2}$ polluters (Carbon Dioxide Information Analysis Center, CDIAC, 2014) and it is under increasing pressure from the EU to ensure improvements in environmental protection given that the EU accession process expects Turkey to introduce some fundamental reforms related to environmental standards and sustainable development (Republic of Turkey Ministry of Foreign Affairs, 2013). On the other hand, Turkey is also committed to stimulating output and economic development via tourism-led growth, as stated in its 'Tourism Strategy for Turkey - 2023' (High Planning Commission, 2007). Turkey's tourism strategy focuses exclusively on the promotional efforts to stimulate 'inbound tourism' as a catalyst for tourism development and economic growth. This makes the choice of Turkey as our context (and our choice of international tourist arrivals as a proxy for tourism development) particularly timely (and appropriate) from a policy agenda perspective.

\section{METHODOLOGY}

\section{Theoretical setting}


Our starting point is that tourism development might be a determinant of environmental pollution (proxied by $\mathrm{CO}_{2}$ emissions). Another important determinant of $\mathrm{CO}_{2}$ emissions, as discussed earlier, is energy use. We, therefore, add energy consumption as a regressor in the function modelling the relationship between $\mathrm{CO}_{2}$ emissions and real income postulated under the EKC framework (see also Stern, 2004). In tourist destination countries, it is expected that tourism leads to an increase in energy use and real income (tourism-led growth) and, therefore, in the level of air pollution. Therefore, the following extended EKC model is proposed:

$\mathrm{CO}_{2 \mathrm{t}}=\mathrm{f}\left(y^{\beta_{1}}, y^{2^{\beta_{2}}}, E_{t}^{\beta_{3}}, T_{t}^{\beta_{4}}\right)$

where $\mathrm{CO}_{2}$ is carbon dioxide emissions $(\mathrm{kt}), \mathrm{E}$ is energy consumption (kt of oil equivalent), $\mathrm{y}$ is real income, and $\mathrm{y}^{2}$ is the square of real income (the standard measure of exponential income adopted in all the studies that have tested the EKC hypothesis). $\mathrm{T}$ stands for tourism development (proxied by international tourist arrivals into Turkey).

Model (1) can be expressed in long-run, logarithmic form as:

$\ln C O 2_{t}=\beta_{0}+\beta_{1} \ln y_{t}+\beta_{2} \ln y_{t}^{2}+\beta_{3} \ln y_{t}+\beta_{4} \ln T_{t}+\varepsilon_{t}$

where $\varepsilon$ is an error term expected to possess white noise properties. As for the expected sign of the coefficients, both $\beta_{1}$ and $\beta_{4}$ should be positive. With respect to $\beta_{2}$ and $\beta_{3}$, if the EKC hypothesis holds true, $\beta_{2}$ should be positive whilst the sign of $\beta_{3}$ should be negative since the EKC postulates that at exponential income levels environmental degradation should decline. Should $\beta_{3}$ be statistically insignificant, this would imply a monotonic increase in the relationship between $\mathrm{CO}_{2}$ emissions and income. 
As cogently argued by Dinda (2004), the EKC is a long-run phenomenon.

Nevertheless, it can still be instructive to estimate also a short-run model, if only to compare the model's behaviour in the short- vis-à-vis the long-run. Moreover, it must be recognized that the dependent variable in equation (2) may not immediately adjust to its equilibrium level. Hence, in order to gauge the speed of adjustment between the shortand long-run, we also estimate the following Error Correction Model (ECM):

$$
\begin{aligned}
\Delta \ln C O 2_{t}=\beta_{0} & +\sum_{i=1}^{n} \beta_{1} \Delta \ln C O 2_{t-j}+\sum_{i=0}^{n} \beta_{2} \Delta \ln y_{t-j} \\
& +\sum_{i=0}^{n} \beta_{3} \Delta \ln y_{t-j}^{2}+\sum_{i=0}^{n} \beta_{4} \Delta \ln E_{t-j}+\sum_{i=0}^{n} \beta_{5} \Delta \ln T_{t-j}+\beta_{6} \varepsilon_{t-1}+u_{t}
\end{aligned}
$$

where $\Delta$ represents a change in $\mathrm{CO}_{2}, \mathrm{E}, \mathrm{y}, \mathrm{y}^{2}$, and $\mathrm{T}$, and $\varepsilon_{\mathrm{t}-1}$ is the one period lagged error correction term (ECT) estimated from equation (2). The ECT shows how quickly the disequilibrium between the short- and long-run value of the dependent variable $\left(\mathrm{CO}_{2}\right)$ is eliminated. The expected sign of the ECT coefficient is negative.

\section{Data and econometric approach}

To remove seasonality issues stemming from both tourism and energy consumption data, we use annual series covering a very long period, from 1960 to 2009 . The series end at 2009 due to data availability. Data are collected from the World Development Indicators (World Bank, 2012) except for the tourist arrival series, which are obtained from the Turkish Statistical Institute (TURKSTAT, 2013). Consistent with the proxies of choice in previous studies, energy consumption is measured using energy use (E) (kt of oil equivalent), environmental pollution by carbon dioxide $\left(\mathrm{CO}_{2}\right)$ emissions $(\mathrm{kt})$ produced 
during consumption of solid, liquid, and gas fuels and gas flaring, income (y) by using GDP in constant terms $(2000=100)$, and squared income $\left(\mathrm{y}^{2}\right)$ by using squared GDP $(2000=100)$. Tourism development, proxied by tourist arrivals, is measured by the number of international visitors (T) who stay in tourist establishments (i.e., 'tourists' rather than 'same-day visitors'). International visitors are people arriving into Turkey (by airway, railway, roadway, seaway, and excursion), with a nationality other than Turkish as defined by the name of the country on the visitor's passport.

Our econometric approach can be summarized as follows. First, unit root tests by Carrion-i-Silvestre et al. (2009) that allow for multiple structural breaks are carried out. Second, cointegration tests by Maki (2012) are employed to establish the existence of a cointegrating vector in equation (2). Finally, long- and short-run coefficients are estimated by means of the DOLS method (Stock and Watson, 1993) and an ECM, respectively.

Most approaches that consider structural breaks while testing for unit roots limit consideration to one or two structural breaks (see, for example, Lumsdaine and Papell, 1997). The newest unit root testing technique is the one developed by Carrion-i-Silvestre et al. (2009) which accounts for up to five breaks in the series. This allows us to place greater confidence in the unit root test results.

The Carrion-i-Silvestre et al. (2009) unit root test identifies structural break points by using a quasi-GLS (Generalized Least Squares) algorithm that minimises the residual sum of squares. On the basis of the stochastic data generation process (DGP) $y_{t}=d_{t}+\mu_{t}\left(\right.$ where $\mu_{t}=\alpha \mu_{t-1}+v_{t}$ for $\left.\mathrm{t}=0,1, \ldots . \mathrm{T}\right)$, five different statistics to test for the null hypothesis of a unit root under multiple structural breaks are developed: 


$$
\begin{aligned}
& P_{T}\left(\lambda^{0}\right) \\
& =\frac{\left[S\left(\bar{\alpha}, \lambda^{0}\right)-\bar{\alpha} S\left(1, \lambda^{0}\right)\right]}{S^{2}\left(\lambda^{0}\right)} \\
& \operatorname{MP}_{T}\left(\lambda^{0}\right) \\
& =\frac{\left[c^{-2} T^{-2} \sum_{t=1}^{T} \tilde{y}_{t-1}^{2}+(1-\bar{c}) T^{-1} \tilde{y}_{T}^{2}\right]}{s\left(\lambda^{0}\right)^{2}} \\
& M Z_{\alpha}\left(\lambda^{0}\right)=\left(T^{-1} \tilde{y}_{T}^{2}-s\left(\lambda^{0}\right)^{2}\right)\left(2 T^{-2} \sum_{t=1}^{T} \tilde{y}_{t-1}^{2}\right)^{-1} \\
& M S B\left(\lambda^{0}\right) \\
& =\left(s\left(\lambda^{0}\right)^{-2} T^{-2} \sum_{t=1}^{T} \tilde{y}_{t-1}^{2}\right)^{1 / 2} \\
& M Z_{t}\left(\lambda^{0}\right)=\left(T^{-1} \tilde{y}_{T}^{2}-s\left(\lambda^{0}\right)^{2}\right)\left(4 s\left(\lambda^{0}\right)^{2} T^{-2} \sum_{t=1}^{T} \tilde{y}_{t-1}^{2}\right)^{1 / 2}
\end{aligned}
$$

The asymptotic critical values are generated through a bootstrapping approach. Rejection of the null hypothesis indicates the absence of a unit root. 
Standard cointegration tests that do not account for the existence of structural breaks are likely to provide biased results. Various approaches are available from relevant literature to deal with this risk by allowing for consideration of one or two breaks in the series. However, especially when considering a long sample period, the risk of incurring in more than two structural breaks affecting the DGP constitutes a serious possibility which, if undetected, may compromise the reliability of the results. To address this issue, we employ the newest cointegration test developed by Maki (2012) that allows for consideration of up to five structural breaks.

In the algorithm of Maki's (2012) cointegration test, every period is assumed to be a possible breaking point and a t-statistic for each period is computed. Periods with the lowest t-ratios are identified as breaking points. Maki (2012) developed four different models in order to test for cointegration.

Model 1, with a break in the intercept and without trend:

$$
y_{t}=\mu+\sum_{i=1}^{k} \mu_{i} K_{i, t}+\beta x_{t}+v_{t}
$$

Model 2, with a break in the intercept and coefficients, and without trend:

$$
y_{t}=\mu+\sum_{i=1}^{k} \mu_{i} K_{i, t}+\beta x_{t}+\sum_{i=1}^{k} \beta_{i} x_{i} K_{i, t}+v_{t}
$$

Model 3, with a break in the intercept and coefficients, and with trend:

$$
y_{t}=\mu+\sum_{i=1}^{k} \mu_{i} K_{i, t}+\not x+\beta x_{t}+\sum_{i=1}^{k} \beta_{i} x_{i} K_{i, t}+v_{t}
$$

Model 4, with a break in the intercept, coefficients, and trend: 


$$
y_{t}=\mu+\sum_{i=1}^{k} \mu_{i} K_{i, t}+\gamma t+\sum_{i=1}^{k} \gamma_{i} t K_{i, t}+\beta x_{t}+\sum_{i=1}^{k} \beta_{i} x_{i} K_{i, t}+v_{t}
$$

where $\mathrm{K}_{\mathrm{i}}$ stands for dummy variables that are defined by Maki (2012) as:

$$
K_{i}=\left\{\begin{array}{cc}
1 & \text { when } \mathrm{t}>\mathrm{T}_{\mathrm{B}} \\
0 & \text { otherwise }
\end{array}\right.
$$

where $T_{B}$ stands for break point. Critical values to test for the null of 'no cointegration' under structural breaks are computed through Monte Carlo simulations (see Maki, 2012).

If a cointegrating vector is determined, the next step is to estimate the long-run coefficients of equation (2) via the DOLS approach. Stock and Watson (1993) suggest the inclusion of differenced and lagged structures of independent variables in addition to their level forms, so as to obtain consistent estimators by eliminating any autocorrelation, simultaneity and endogeneity problems. The DOLS model to estimate equation (2) can be re-expressed as:

$$
\begin{aligned}
\ln C O 2_{t}=\alpha_{1}+ & \alpha_{2} \ln E_{t}+\alpha_{3} \ln y_{t}+\alpha_{4} \ln y_{t}^{2}+\alpha_{5} \ln T_{t} \\
& +\sum_{i=-q}^{q} \beta_{i} \Delta \ln E_{t-i}+\sum_{i=-q}^{q} \gamma_{i} \Delta \ln y_{t-i}+\sum_{i=-q}^{q} \delta_{i} \Delta \ln y_{t-i}^{2}+\sum_{i=-q}^{q} \mu_{i} \Delta \ln T_{t-i}+\varpi D_{i}+\varepsilon_{t}
\end{aligned}
$$

where $\mathrm{q}$ stands for the lag structure to be determined by the Akaike Information Criterion (AIC), and $t$ is a time trend. $\mathrm{D}_{\mathrm{i}}$ stands for dummy variables of up to five year breaks.

After estimating the DOLS long-run coefficients, short-run ECM coefficients are estimated. In addition to the variables of equation (3), year breaks are included in the dynamic model to check their statistical significance. Then, the ECM of interest becomes: 


$$
\begin{aligned}
\Delta \ln C O 2_{t}=\beta_{0}+\sum_{i=1}^{n} & \beta_{1} \Delta \ln C O 2_{t-j}+\sum_{i=0}^{n} \beta_{2} \Delta \ln E_{t-j} \\
& +\sum_{i=0}^{n} \beta_{3} \Delta \ln y_{t-j}+\sum_{i=0}^{n} \beta_{4} \Delta \ln y_{t-j}^{2}+\sum_{i=0}^{n} \beta_{5} \Delta \ln T_{t-j}+\sum_{i=1}^{5} \beta_{6} D_{i}+\beta_{7} \varepsilon_{t-1}+u_{t}
\end{aligned}
$$

where $D_{i}$ stands for up to five dummy variables to account for relevant year breaks.

\section{EMPIRICAL ANALYSIS AND RESULTS}

Table 1 provides the unit root test results, which suggest five structural break points in the series. By taking these breaks into account, all the series under consideration emerge as non-stationary in levels since the null of 'no unit root' cannot be rejected at the customary significance level in the case of each variable. All the series become stationary in their first difference. Hence, $\operatorname{lnCO} 2, \operatorname{lnGDP}, \operatorname{lnE}$, and $\ln \mathrm{T}$ are all integrated of order one, indicating that the model of equation (1) lends itself to forming a cointegrating relationship.

\section{$<$ Tables 1 and 2 here $>$}

We can now safely procede to test for cointegration by employing Maki's (2012) approach. As can be seen from Table 2, the null hypothesis of 'no cointegration' can be rejected under the existence of various (structural) year breaks and for the four models suggested by Maki (2012). Equation (1) cointegrates and the estimated parameters are robust in the long-run. Year breaks that have been identified are added to the estimation of the long-run coefficients via dummy variables. As shown in Table 3, which reports the 
long-run estimates, the break of 1971 is found to exert a statistically significant and positive impact on carbon emissions (by 0.05).

The DOLS long-run estimates are reported in Table 3. The income coefficient is significantly positive, whilst it turns negative for squared income. Specifically, the estimated coefficients for lny and $l n y^{2}$ are 8.33 and -0.36 , respectively. These estimates are broadly comparable to those reported by Halicioglu (2009), who also examined the Turkish case, reporting estimates of 12.31 for income, and -0.83 for squared income. The slight difference in the magnitude of these estimates could be attributed to the different length of the sample period (Halicioglu's sample period ended at 2005 whilst ours extends to 2009), the econometric technique employed (Halicoglu relied on standard cointegration and ARDL techniques), and to the model specification itself, since our extended EKC framework also controls for the role of tourism.

\section{< Table 3 here >}

Most importantly, our findings are consistent with the prediction of the EKC hypothesis, suggesting that although as income rises $\mathrm{CO}_{2}$ emissions too increase, at exponential levels of growth (squared income), this relationship turns negative, resulting in declining levels of environmental pullution, as can be evinced by the significantly negative $\ln y^{2}$ coefficient in Table $3(-0.36)$.

Consistent with prior expectations and previous findings from the energy literature, we also find that energy consumption exerts a positive and statistically significant impact on carbon emissions. Our estimate of 0.90 compares well to the estimate of 0.78 found by Halicioglu (2009) who also used $\mathrm{CO}_{2}$ emissions as his pollutant measure. 
Significantly, the estimated elasticity coefficient of tourist arrivals is also positively significant, indicating that a $1 \%$ increase in the volume of tourist arrivals leads to a rise of $5 \%$ in $\mathrm{CO}_{2}$ emissions (0.05).

Our result, however, would seem, prima facie, to be at odds with recent evidence published by Lee and Brahmasrene (2013) according to which, 'contrary to what many would expect' (ibid, p 74), tourism does not lead to increased $\mathrm{CO}_{2}$ emissions (their estimated coefficient is -0.105). Nevertheless, their evidence does not emerge from an EKC-extended model, and it is based on a panel of EU member countries (1988-2009) which, of course, does not include Turkey. Moreover, as acknowledged by Lee and Brahmasrene (2013) themselves, their result of a negative effect of tourism receipts on $\mathrm{CO}_{2}$ emissions is largely attributable to the EU-based 2007 agenda for a sustainable and competitive tourism (the EC agenda to promote environmental sustainability). Plots of conventional and extended EKC functions are presented in Figure 1.

\section{$<$ Table 4 here >}

The results from the ECM aimed at shedding light on the speed of adjustment to the long term equilibrium level are reported in Table 4. Conforming to a priori expectations, the estimated ECT is significantly negative, with a plausible magnitude of 0.4987 that compares well to that reported in relevant studies (for example, Ozturk and Acaravci 2010, report an ECT value of -0.429). This implies that short term deviations of the variables from their long-run cointegrating level are corrected with a $49.87 \%$ speed of adjustment in each period, taking about two periods to return to equilibrium. The estimated short-run coefficients of Table 4 are very similar to those of Table 3. However, the coefficient of the tourism variable is not statistically significant in the short-run 
model. This result, which confirms the usefulness of estimating a short-run model alongside an equilibrium level relationship even in the context of the EKC framework, suggests that it is through the channel of energy consumption that tourism development affects economic growth and environmental pollution in the long term. It is also worth mentioning that the coefficient of the dummies for the two year breaks of 1984 and 1992 are statistically significant in the ECM regression. In terms of diagnostics, Figure 2 displays the plot of cumulative sum (CUSUM) and CUSUM of squares test statistics on recursive residuals, both of which fall within the critical bounds at the $5 \%$ significance level, thus confirming the stability of the estimated paramaters.

$<$ Figure 1 here >

$<$ Figure 2 here >

So, granted that tourism development significantly contributes to $\mathrm{CO}_{2}$ emissions in the long term, and that it is part of a cointegrating relationship with energy consumption, growth and environmental pollution; what is the exact role of tourism development in shaping the EKC? To answer this question, and hence isolate the effect of both energy consumption and tourism development on the relationship between income and environmental pollution postulated by the EKC hypothesis, we have re-estimated a conventional EKC model, one which adds to it only the energy variable, and a conventional EKC model that also includes the tourism development variable.

\section{$<$ Table 5 here $>$}

The results of these additional estimations are presented in Table 5. These results lend themselves to a straightforward comparison with the results of Table 3. As can be seen from Table 5, the inclusion of energy consumption or of tourism development to the 
conventional EKC specification only affects the magnitude of the income coefficients (bringing them closer to the magnitudes emerging from estimation of our extended model in Table 3), with no changes to either their sign or statistical significance. Indeed, in line with the EKC hypothesis, all three regression results reported in Table 5 show a positive coefficient for income, and a negative coefficient for squared income.

These results are also consistent with those of Table 3 which are based on our tourism-extended EKC model, though in the latter specification (which records the strongest explanatory power), the magnitudes of the income coefficients are slightly lower than those reported in Table 5. In the regression that includes energy consumption, the estimated $\operatorname{lnE}$ coefficient (0.49) is quite a bit smaller than that of Table 3 (0.90), while in the regression that includes tourism development, the estimated $\ln \mathrm{T}$ coefficient $(0.04)$ is very close to that reported in Table $3(0.05)$. We have, therefore, evidenced the statistically significant and distinct effects accounted for by both energy consumption and tourism development on both $\mathrm{CO}_{2}$ emissions and the baseline $\mathrm{EKC}$ model.

Another check called for re-estimation by employing a measure of $\mathrm{CO}_{2}$ emissions that accounts for the carbon footprint associated with international tourists' travel to Turkey. Accordingly, we also re-run the regression of the 'EKC model with $\ln \mathrm{T}$ ' using a measure that includes international $\mathrm{CO}_{2}$ emissions from international aviation and maritime transport for Turkey (data obtained from CDIAC, 2014). The results of this additional exercise (see Note of Table 5) are broadly consistent with those obtained previously, though the estimated elasticities are larger for all the coefficients. This pattern can be explained by the fact that, whilst in previous estimations $\mathrm{CO}_{2}$ emissions from aviation were externalized to the global community, their effects are being estimated 
now, with a resulting increase in the magnitude of the estimated coefficients and a concomitant amplification of their positive and negative impacts.

To ascertain the robustness of the results obtained, we also re-estimated all the regression models examined above using 'per capita' series. As per the models estimated previously, the residuals continued to display white noise properties. None of these reestimations (available from the authors) led to results that altered our previous findings. Furthermore, our 'per capita' estimation of the extended EKC model also allowed us to compute the exact 'turning point' at which environmental damage can begin to recede, with the (per capita) income figure at which (per capita) $\mathrm{CO}_{2}$ emissions can start going downwards estimated at 6,179 US\$. This is a very plausible figure as can be gauged by Dinda's (2004, p.442) survey of relevant literature, according to which 'For most of the pollution indicators, the estimated turning point lies within the income range US\$3,00010,000 '. Turkey's current GDP per capita is 15,353 US\$ (IMF, 2014). This means that Turkey is already within the range that allows for a path of decline in emissions. Growth forecasts produced by the IMF expect Turkey's current GDP per capita to rise by $27 \%$, to 19,505 US $\$$ by 2019 (IMF, 2014). Our estimated $\ln ^{2}$ coefficient (from Table 3 ) is -0.36 , indicating that a one per cent increase in 'squared income' $\left(15,353^{2} / 100\right)$ - which is equivalent to a rise of GDP per capita of 2,357 US\$ - would lead to a $36 \%$ decrease in $\mathrm{CO}_{2}$ emissions. Since the estimated increase of Turkey's per capita GDP by 2019 is, going by the IMF (2014) estimates, 4,152 US\$, our model would suggest a concomitant decrease in Turkey's $\mathrm{CO}_{2}$ emissions of $63.4 \%$ by 2019 , if the IMF's per capita growth estimates prove to be true. 


\section{FURTHER DISCUSSION AND CONCLUSIONS}

Theoretically, the study makes a contribution by highlighting the rationale for the integration of tourism development within the EKC model, effectively linking the tourism-led growth hypothesis with the EKC framework. This provides a blueprint for further theoretical development of a testable model extension that integrates sectors of economic activity (tourism in our case) within the EKC framework.

Our results provide empirical support to the above supposition, revealing that a long-run relationship exists between tourism development and $\mathrm{CO}_{2}$ emissions in Turkey through the channels of energy consumption and real income growth. Our regression results also confirm the validity of a conventional EKC model for Turkey, whereby at exponential levels of income growth, the level of environmental degradation (measured by $\mathrm{CO}_{2}$ emissions) is expected to decrease.

Significantly, we also find empirical support for an extended EKC model that controls for both energy consumption and tourism development, in spite of the tourism development positive impact upon environmental degradation. This extended EKC model (which proves to be the specification with the highest explanatory power), displays coefficients for both income and squared income of the same sign but of slightly smaller magnitude than those estimated from a conventional EKC model. Having shown the distinct and statistically significant effect of tourism development (and energy consumption) on both $\mathrm{CO}_{2}$ emissions and the conventional EKC function, we can conclude that our evidence suggests that Turkey has the potential for 'growing itself out of' its environmental problems, at virtuous levels of economic growth, also through tourism-led growth. 


\section{Policy implications}

It has been shown that tourism development leads to a deterioration in air quality in the case of Turkey. But our evidence also highlights that at considerably higher levels of income growth (including tourism-led growth), the level of environmental degradation is likely to recede. It follows that conservation policies should be well-balanced with macroeconomic targets aimed at stimulating economic growth since pursuing a new policy that promotes a low-carbon economy at all costs (including restrictions in tourismrelated investments in infrastructure and development) would simultaneously limit the rate of economic growth. This raises the importance of balancing environmental protection policies in Turkey with the critical need for strengthening policies that are aimed at the proverbial tourism-led growth.

We are cognisant that some readers may 'raise eyebrows' to the core implication that flows from our findings since they may be seen to send the dangerous message that the governmental remit of environmental protection could be ignored. On the contrary, our argument is that the evidence for Turkey, just like the EKC hypothesis itself, evinces that environmental protection may well be best served by ensuring that economies that display EKC-like features, be allowed to grow out of their environmental problems.

As noted earlier, Turkey is under increasing pressure from the EU to ensure improvements in environmental protection given that the EU accession process expects Turkey to introduce some fundamental reforms related to environmental standards. As outlined in the 'EU Integrated Environmental Approximation Strategy (2007 - 2023)' (Republic of Turkey, 2006) developed to meet the EU's environmental requirements 
preparations for EU membership, harmonization with these environmental norms presents considerable legal, administrative and financial challenges, all of which place the environmental protection issues high on the political agenda. The specific EU norms pertain to, to name but a few, air and water quality, noise pollution, waste management and nature protection. It is evident that implementation of these measures (as with any operation of sustainability principles for any sector of economic activity, including tourism), necessitates hard political choices, and decisions based upon complex economic and environmental trade-offs, for example, by redirecting financial resources and investments away from sectors that may hold the key to higher economic growth, towards the technology needed to establish, enhance or modernize the facilities and infrastructure conducive to meeting environmental protection policy objectives. The literature has already provided evidence in this respect. For example, Jorgenson and Wilcoxen (1990) found that compliance with more stringent environmental regulations slowed the US economy GDP growth between 1974 and 1985 by $2.4 \%$.

So what specific recommendations for the Turkish government flow from this? It is imperative to ensure that environmental protection standards are not pursued at the expense of policies in support of economic growth, including tourism-led growth. It is precisely in 'striking the right balance' the major task that lies ahead for the formulation of an appropriate policy response to the 'economic growth-environmental protection' dilemma since we too acknowledge the wide ranging and potentially devastating effects of environmental degradation. In practical terms this means, for example, strengthening the institutional capacity to analyze the economic growth prospects of proposed tourism development policies and projects whilst 'factoring in' the significant long-term 
environmental benefits of such developments in addition to their short-term environmental costs.

\section{Limitations and future research}

Despite the contributions of our findings, some caveats need to be borne in mind. First, our results for Turkey are not necessarily generalisable since, as gauged by the cogent analysis by List and Gallet (1999), the 'one size fit all' EKC prediction is likely to be contrasted with evidence of distinct experiences of individual countries. A profitable avenue for future research, therefore, would be to replicate our extended EKC model in other developing countries (such as China, India and Brazil) which, like Turkey, are faced by the policy dichotomy of tourism-led growth on one side and environmental protection on the other. There is also a room to investigate similar issue for the other major tourist destination countries.

Second, although the environmental measure that we have employed $\left(\mathrm{CO}_{2}\right.$ emissions) has been pointed out as one of the major global pollutants, we acknowledge that the findings of estimation of an EKC-type relationship are likely to be sensitive to the type of pollutant measured. This means that other air, noise and water pollutants may behave differently vis-à-vis economic growth. Accordingly, taking into account different indicators of environmental pollution or different forms of ecological degradation stemming from tourism development provides another potential extension. Furthermore, not only tourism but also the other economic sectors can be also considered if they are sources of air pollution such as industry, transportation, and urban development. 


\section{REFERENCES}

Adamou A, Clerides S. 2009. Tourism, development and growth: international evidence and lessons for Cyprus. Cyprus Economic Policy Review 3(2): 3-22.

Akbostanci E, Türüt-Asik S, Tunç GI. 2009. The relationship between income and environment in Turkey: is there an environmental Kuznets curve? Energy Policy 37(3): 861-867.

Akkemik AK. 2012. Assessing the importance of international tourism for the Turkish economy: a social accounting matrix analysis. Tourism Management 33(3): 790801.

Ang JB. 2008. Economic development, pollutant emissions and energy consumption in Malaysia. Journal of Policy Modeling 30(2): 271-278.

CDIAC. 2014. United States department of energy (http://cdiac.ornl.gov/)

Carrion-i-Silvestre JL, Kim D, Perron P. 2009. GLS-based unit root tests with multiple structural breaks under both the null and the alternative hypotheses. Econometric Theory 25(6): 1754-1792.

Coondoo D, Dinda S. 2002. Causality between income and emission: a country group specific econometric analysis. Ecological Economics 40(3): 351-367.

Dinda S. 2004. Environmental Kuznets curve hypothesis: a survey. Ecological Economics. 49(4): 431-455.

Friedl B, Getzner M. 2003. Determinants of $\mathrm{CO}_{2}$ emissions in a small open economy. Ecological Economics 45(1): 133-148.

Gössling S. 2002. Global environmental consequences of Tourism. Global Environmental Change 12(4): 283-302. 
Grossman GM, Krueger AB. 1991. Environmental impacts of the North American free trade agreement. NBER Working Paper 3914.

Halicioglu F. 2009. An econometric study of $\mathrm{CO}_{2}$ emissions, energy consumption, income and foreign trade in Turkey. Energy Policy 37(3): 1156-1164.

He J, Richard P. 2010. Environmental Kuznets curve for $\mathrm{CO}_{2}$ in Canada. Ecological Economics 69(5): 1083-1093.

High Planning Commission. 2007. Tourism strategy of Turkey - 2023 and activity plan for tourism strategy for Turkey 2007-2013. Official Journal of the High (Supreme) Planning Commission 26450.

Holtz-Eakin D, Selden TM. 1992. Stocking the fires? $\mathrm{CO}_{2}$ emissions and economic growth. National Bureau of Economic Research.

IMF. 2014. World Economic Outlook Database, April edition.

Jorgenson DW, Wilcoxen PJ. 1990. Environmental regulation and U.S. economic growth. The RAND Journal of Economics 21(2): 314-340.

Katircioglu, S.T. (2014a), Testing the Tourism-Induced EKC Hypothesis: The Case of Singapore, Economic Modeling, 41, 383-391.

Katircioglu, S.T. (2014b), International Tourism, Energy Consumption, and Environmental Pollution: The Case of Turkey, Renewable \& Sustainable Energy Reviews, 36, 180-187.

Katircioglu, S.T., Feridun, M., and Kilinc, C. (2014), Estimating Tourism-Induced Energy Consumption and CO2 Emissions: The Case of Cyprus, Renewable \& Sustainable Energy Reviews, 29, 634-640. 
Katircioglu ST. 2009. Revisiting the tourism-led growth hypothesis for Turkey using the bounds test and Johansen approach for cointegration. Tourism Management 30(1): $17-20$.

Kuznets S. 1955. Economic growth and income inequality. American Economic Review 45(1): $1-28$.

Lee J, Brahmasrene T. 2013. Investigating the influence of tourism on economic growth and carbon emissions: evidence from panel analysis of the European Union. Tourism Management 38: 69-76.

Lin TP. 2010. Carbon dioxide emissions from transport in Taiwan's national parks. Tourism Management 31(2): 285-290.

Lindmark M. 2002. An EKC-pattern in historical perspective: carbon dioxide emissions, technology, fuel prices and growth in Sweden, 1870-1997. Ecological Economics 42(2): 333-347.

List JA, Gallet CA. 1999. The environmental Kuznets curve: does one size fit all? Ecological Economics 31(3): 409-423.

Lumsdaine RL, Papell DH. 1997. Multiple trend breaks and the unit root hypothesis. The Review of Economics and Statistics 79(2): 212-218.

Luzzati T, Orsini M. 2009. Natural environment and economic growth: looking for the energy-EKC. Energy 34(3): 291-300.

Maki D. 2012. Tests for cointegration allowing for an unknown number of breaks. Economic Modelling 29(5): 2011-2015.

Ozturk I, Acaravci A. 2010. $\mathrm{CO}_{2}$ emissions, energy consumption and economic growth in Turkey. Renewable and Sustainable Energy Reviews 14(9): 3220-3225. 
Panayotou T. 1993. Empirical Tests and Policy Analysis of Environmental Degradation of Different Stages of Economic Development. International Labour Office, Geneva.

Republic of Turkey. 2006. EU Integrated Environmental Approximation Strategy (2007 - 2023). Ministry of Environment and Forestry, Ankara, Turkey.

Republic of Turkey Ministry of Foreign Affairs. 2013. Relations with the European Union in the Field of Environment (http://www.mfa.gov.tr).

Republic of Turkey Prime Ministry. 2010. Investment Support and Promotion Agency of Turkey. Turkish Tourism Industry Report, Ankara, Turkey.

Shafik N, Bandyopadhyay S. 1992. Economic Growth and Environmental Quality: Time Series and Cross Country Evidence. World Bank, Washington DC, USA.

Solarin SA. 2014. Tourist arrivals and macroeconomic determinants of $\mathrm{CO}_{2}$ emissions in Malaysia. Anatolia: An International Journal of Tourism and Hospitality Research 25(2): 228-241.

Soytas U, Sari R, Ewing BT. 2007. Energy consumption, income, and carbon emissions in the United States. Ecological Economics 62(3): 482-489.

Stern DI. 2004. The rise and fall of the environmental Kuznets curve. World Development 32(8): 1419-1439.

Stock J, Watson MW. 1993. A simple estimator of cointegrating vectors in higher order integrated systems. Econometrica 61(4): 783-820.

Tsai K-T, Lin T-P, Hwang R-L, Huang Y-J. 2014. Carbon dioxide emissions generated by energy consumption of hotels and home stay facilities in Taiwan. Tourism Management 42: 13-21. 
TURKSTAT. 2013. Statistical Indicators (http://www.turkstat.gov.tr)

UNWTO World Tourism Barometer. 2009. International Tourism Challenged by

Deteriorating World Economy (http://www.unwto.org)

World Bank. 2012. World Development Indicators (http://www.worldbank.org)

Zhang X-P, Cheng X-M. 2009. Energy consumption, carbon emissions, and economic growth in China. Ecological Economics 68(10): 2706-2712. 


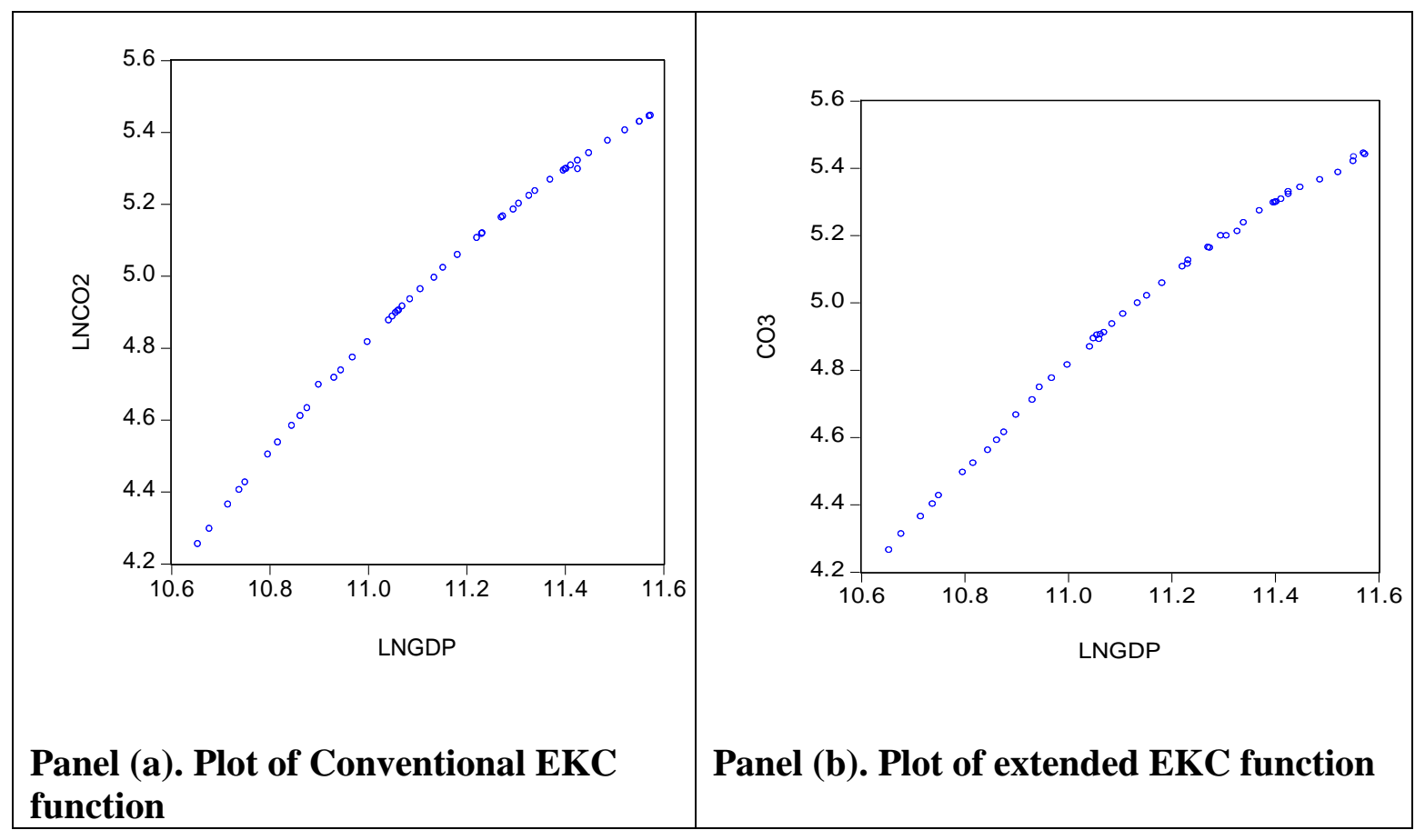

Figure 1. EKC functions 


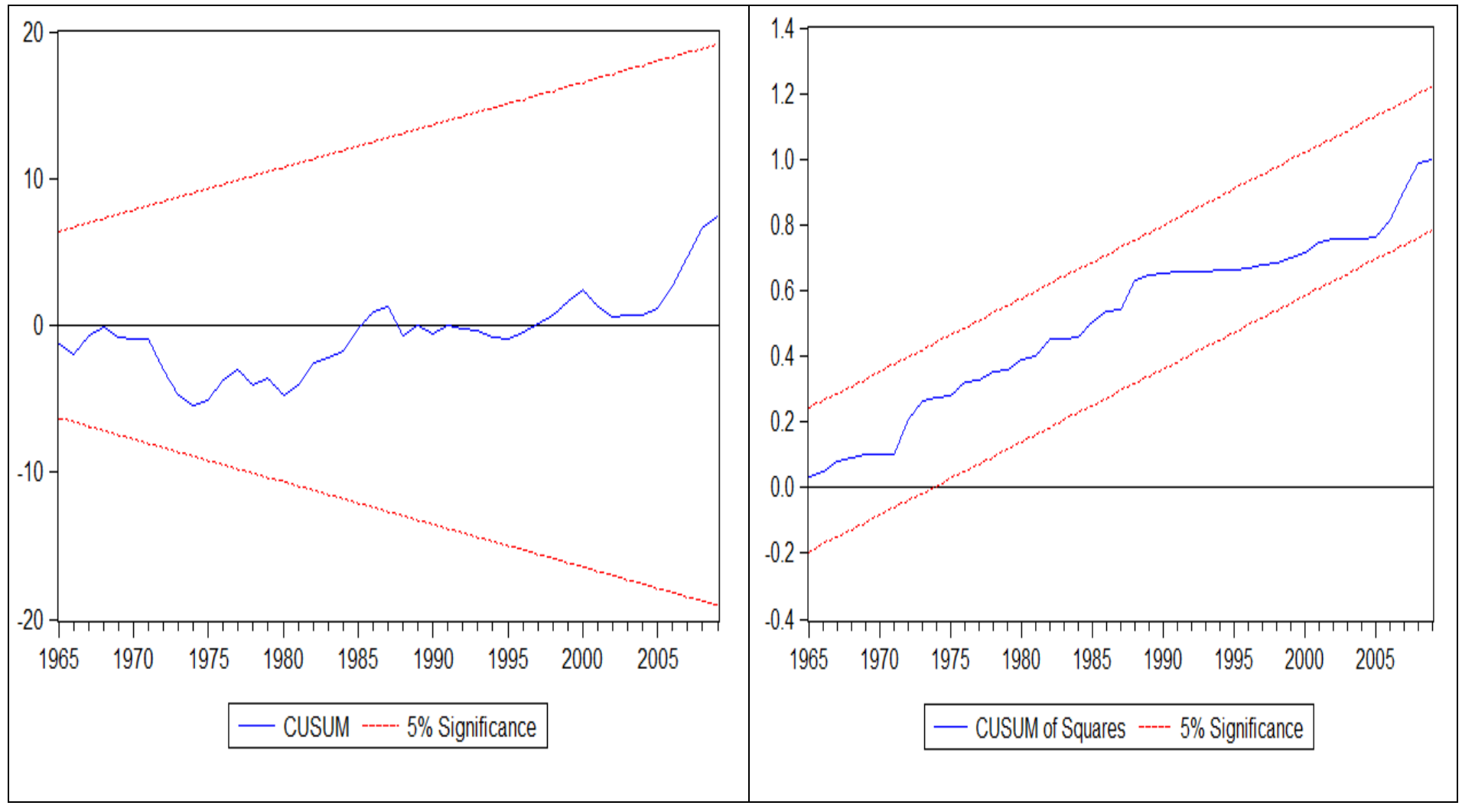

Figure 2. Plot of CUSUM and CUSUM of squares of recursive residuals 
Table 1. Unit root tests

\begin{tabular}{|c|c|c|c|c|c|c|}
\hline & \multicolumn{5}{|c|}{ Levels } & \multirow[t]{2}{*}{ Year breaks } \\
\hline & $\mathrm{P}_{\mathrm{T}}$ & $\mathrm{MP}_{\mathrm{T}}$ & $\mathrm{MZ}_{\alpha}$ & MSB & $\mathrm{MZ}_{\mathrm{t}}$ & \\
\hline $\operatorname{lnCO}_{2}$ & $\begin{array}{c}19.92 \\
{[8.01]}\end{array}$ & $\begin{array}{l}16.99 \\
{[8.01]}\end{array}$ & $\begin{array}{c}-20.52 \\
{[-42.49]}\end{array}$ & $0.15[0.10]$ & $\begin{array}{c}-3.17 \\
{[-4.60]}\end{array}$ & 1977; 1987; 1994; 1999; 2004 \\
\hline Lny & $\begin{array}{l}20.01 \\
{[9.19]}\end{array}$ & $\begin{array}{l}19.00 \\
{[9.19]}\end{array}$ & $\begin{array}{c}-24.07 \\
{[-46.83]}\end{array}$ & $0.13[0.10]$ & $\begin{array}{c}-3.34 \\
{[-4.83]}\end{array}$ & $1971 ; 1978 ; 1985 ; 1994 ; 2000$ \\
\hline $\ln \mathrm{E}$ & $\begin{array}{c}18.84 \\
{[8.52]}\end{array}$ & $\begin{array}{l}17.36 \\
{[8.52]}\end{array}$ & $\begin{array}{c}-22.56 \\
{[-43.77]}\end{array}$ & $0.14[0.10]$ & $\begin{array}{l}-3.25 \\
{[-4.67]}\end{array}$ & $1973 ; 1978 ; 1993 ; 1998 ; 2003$ \\
\hline $\ln \mathrm{T}$ & $\begin{array}{l}19.05 \\
{[9.20]}\end{array}$ & $\begin{array}{l}18.55 \\
{[9.20]}\end{array}$ & $\begin{array}{c}-24.42 \\
{[-47.81]}\end{array}$ & $0.14[0.10]$ & $\begin{array}{l}-3.45 \\
{[-4.87]}\end{array}$ & $1964 ; 1972 ; 1982 ; 1987 ; 1997$ \\
\hline
\end{tabular}

First differences

\begin{tabular}{|c|c|c|c|c|c|}
\hline \multirow{2}{*}{$\Delta \operatorname{lnCO}_{2}$} & $4.23^{*}$ & $4.03^{*}$ & $-23.65^{*}$ & $0.14 *$ & $-3.40 *$ \\
\hline & [5.54] & [5.54] & {$[-17.32]$} & {$[0.16]$} & {$[-2.89]$} \\
\hline \multirow{2}{*}{$\Delta \ln y$} & $4.24 *$ & $4.04 *$ & $-23.67 *$ & $0.14 *$ & $-3.40 *$ \\
\hline & [5.54] & [5.54] & {$[-17.32]$} & {$[0.16]$} & {$[-2.89]$} \\
\hline \multirow{2}{*}{$\Delta \ln E$} & $4.82^{*}$ & $4.62^{*}$ & $-23.60^{*}$ & $0.14 *$ & $-3.30 *$ \\
\hline & [5.54] & [5.54] & {$[-17.32]$} & {$[0.16]$} & {$[-2.89]$} \\
\hline \multirow{2}{*}{$\Delta \ln T$} & $3.70^{*}$ & $3.86^{*}$ & $-23.68^{*}$ & $0.14 *$ & $-3.43 *$ \\
\hline & {$[5.54]$} & {$[5.54]$} & [-17.32] & {$[0.16]$} & -2.89] \\
\hline
\end{tabular}

Notes: Year breaks are determined by using the unit root tests of Carrion-i-Silvestre et al. (2009). * denotes the rejection of the null of a unit root at the 0.05 significance level. Numbers in square brackets are critical values from the bootstrap approach.

Table 2. Maki's (2012) cointegration tests

\begin{tabular}{|c|c|c|c|c|c|}
\hline & $\begin{array}{c}\text { At most one } \\
\text { break }\end{array}$ & $\begin{array}{l}\text { At most two } \\
\text { Breaks }\end{array}$ & $\begin{array}{c}\text { At most three } \\
\text { Breaks }\end{array}$ & $\begin{array}{c}\text { At most four } \\
\text { breaks }\end{array}$ & $\begin{array}{c}\text { At most five } \\
\text { breaks }\end{array}$ \\
\hline Model 1 & $\begin{array}{c}-7.03[-5.65]^{*} \\
(2005)\end{array}$ & $\begin{array}{c}-7.64[-5.83]^{*} \\
(1973 ; 2005)\end{array}$ & $\begin{array}{c}-8.43[-5.99]^{*} \\
(1965 ; 1973 ; 2005)\end{array}$ & $\begin{array}{c}-9.34[-6.13]^{*} \\
(1965 ; 1973 \\
1977 ; 2005)\end{array}$ & $\begin{array}{c}-9.64[-6.30]^{*} \\
(1965 ; 1973 ; 1977 ; 1992 ; \\
2005)\end{array}$ \\
\hline Model 2 & $\begin{array}{c}-7.03[-5.91]^{*} \\
(1963)\end{array}$ & $\begin{array}{c}-7.03[-6.05]^{*} \\
(1963 ; 1969)\end{array}$ & $\begin{array}{c}-7.03[-6.21]^{*} \\
(1963 ; 1969 ; 1980)\end{array}$ & $\begin{array}{c}-7.50[-6.37]^{*} \\
(1963 ; 1969 ; \\
1980 ; 2006)\end{array}$ & $\begin{array}{c}-7.88[-6.49]^{*} \\
(1963 ; 1969 ; 1973 ; 1980 ; \\
2006)\end{array}$ \\
\hline Model 3 & $\begin{array}{c}-7.29[-6.52]^{*} \\
(1971)\end{array}$ & $\begin{array}{c}-8.76[-7.24]^{*} \\
(1971 ; 1984)\end{array}$ & $\begin{array}{c}-9.67[-7.80]^{*} \\
(1971 ; 1984 ; 1990)\end{array}$ & $\begin{array}{c}-10.33[-8.29]^{*} \\
(1971 ; 1977 ; \\
1984 ; 1990)\end{array}$ & $\begin{array}{c}-10.33[-8.86]^{*} \\
(1971 ; 1977 ; 1984 ; 1990 ; \\
1999)\end{array}$ \\
\hline Model 4 & $\begin{array}{c}-7.97[-6.91]^{*} \\
(1971)\end{array}$ & $\begin{array}{c}-8.99[-7.63]^{*} \\
(1971 ; 1984)\end{array}$ & $\begin{array}{c}-9.52[-8.25]^{*} \\
(1971 ; 1984 ; 1992)\end{array}$ & $\begin{array}{c}-9.52[-8.87]^{*} \\
(1971 ; 1984 \\
1992 ; 2002)\end{array}$ & $\begin{array}{c}-9.84[-9.48]^{*} \\
(1971 ; 1978 ; 1984 ; 1992 ; \\
2002)\end{array}$ \\
\hline
\end{tabular}

Notes: Numbers in square brackets are critical values at the 0.05 significance level obtained from Table 1 of Maki (2012). * denotes rejection of the null of 'no cointegration'. Numbers in round brackets are structural (year) breaks as determined by using Maki’s (2012) cointegration test. 
Table 3. Long-run estimates

\begin{tabular}{ccccccc}
\hline & Constant & Lny & $\operatorname{lny}^{2}$ & $\operatorname{lnE}$ & $\operatorname{lnT}$ \\
\hline $\operatorname{lnCO}_{2}$ & $-46.90^{*}$ & $8.33^{*}$ & $-0.36^{*}$ & $0.90^{*}$ & $0.05^{*}$ \\
& {$[-5.92]$} & {$[6.17]$} & {$[-7.25]$} & {$[4.93]$} & {$[2.58]$} \\
$\mathrm{K} 1$ & $\mathrm{~K} 2$ & $\mathrm{~K} 3$ & $\mathrm{~K} 4$ & $\mathrm{~K} 5$ & $\mathrm{R}^{2}$ & $\mathrm{DW}$ \\
\hline $0.05^{*}$ & -0.02 & 0.01 & -0.001 & -0.02 & \multirow{2}{*}{0.99} & 2.58 \\
{$[1.76]$} & {$[0.79]$} & {$[0.66]$} & {$[-0.02]$} & {$[-0.80]$} & & \\
\hline
\end{tabular}

Notes: Numbers in square brackets are t ratios. Autocorrelation and heteroscedasticity problems have been eliminated by means of the Newey-West approach. The model also passes the normality test, with a JarqueBera test statistic $\left(\chi_{\mathrm{JBN}}^{2}\right)$ of 2.78 . The five dummies in the model are: K1 (1971), K2 (1978), K3 (1984), K4 (1992) and K5 (2002) from Model 3 that includes a constant and a deterministic trend. * denotes statistical significance at the 0.05 level.

Table 4. ECM estimates

\begin{tabular}{|c|c|c|c|c|c|c|}
\hline \multirow{4}{*}{$\Delta \operatorname{lnCO}{ }_{2}$} & Constant & $\mathrm{ECT}_{\mathrm{t}-1}$ & $\Delta \ln y$ & $\Delta \ln y^{2}$ & $\Delta \ln E$ & $\Delta \ln \mathrm{T}$ \\
\hline & $\begin{array}{l}0.0023 \\
{[0.696]}\end{array}$ & $\begin{array}{c}-0.4987 * \\
{[-1.516]}\end{array}$ & $\begin{array}{l}9.0878 * \\
{[3.298]}\end{array}$ & $\begin{array}{c}-0.3882 * \\
{[-3.198]}\end{array}$ & $\begin{array}{c}0.7518^{*} \\
{[3.719]}\end{array}$ & \multirow[t]{3}{*}{$\begin{array}{l}-0.0231 \\
{[-0.599]}\end{array}$} \\
\hline & K1 & K2 & K3 & K4 & K5 & \\
\hline & $\begin{array}{l}0.0028 \\
{[0.208]}\end{array}$ & $\begin{array}{l}-0.0201 \\
{[-1.249]}\end{array}$ & $\begin{array}{c}0.0166^{*} \\
{[1.283]}\end{array}$ & $\begin{array}{l}-0.0217^{*} \\
{[-1.6138]}\end{array}$ & $\begin{array}{l}-0.0031 \\
{[-0.218]}\end{array}$ & \\
\hline \multicolumn{7}{|c|}{ Diagnostics test results } \\
\hline
\end{tabular}

Notes: Numbers in square brackets are t ratios. Autocorrelation and heteroscedasticity problems have been eliminated by means of the Newey-West approach. The model also passes the normality test, with a JarqueBera test statistic $\left(\chi_{\text {JBN }}^{2}\right)$ of 2.12. The five dummies in the model are: K1 (1971), K2 (1978), K3 (1984), K4 (1992) and K5 (2002) from Model 3 that includes a constant and a deterministic trend. * denotes statistical significance at the 0.05 level.

Table 5. Conventional EKC model, with energy variable, and with tourism variable

\begin{tabular}{|c|c|c|c|c|c|c|c|c|}
\hline & \multicolumn{2}{|c|}{ Conventional EKC } & \multicolumn{3}{|c|}{ EKC model with $\ln E$} & \multicolumn{2}{|c|}{ EKC model with $\ln T$} & \\
\hline & Lny & Lny $^{2}$ & Lny & $\ln y^{2}$ & $\operatorname{lnE}$ & $\ln y$ & $\ln y^{2}$ & $\ln \mathrm{T}$ \\
\hline $\operatorname{lnCO}_{2}$ & $\begin{array}{l}15.00 * \\
{[14.58]}\end{array}$ & $\begin{array}{c}-0.61 * \\
{[-13.36]}\end{array}$ & $\begin{array}{l}11.27 * \\
{[11.21]}\end{array}$ & $\begin{array}{c}-0.47^{*} \\
{[-11.73]}\end{array}$ & $\begin{array}{c}0.49 * \\
{[3.64]}\end{array}$ & $\begin{array}{l}12.33^{*} \\
{[11.98]}\end{array}$ & $\begin{array}{c}-0.54^{*} \\
{[-12.0]}\end{array}$ & $\begin{array}{c}0.04 * \\
{[4.75]}\end{array}$ \\
\hline & $\begin{array}{l}\mathrm{R}^{2}= \\
0.87\end{array}$ & & $\begin{array}{l}\mathrm{R}^{2}= \\
0.91\end{array}$ & & & $\begin{array}{l}\mathrm{R}^{2}= \\
0.90\end{array}$ & & \\
\hline
\end{tabular}

Notes: Numbers in square brackets are $\mathrm{t}$ ratios. Autocorrelation and heteroscedasticity problems were eliminated by means of the Newey-West approach. All three regressions included a significant constant term and five dummy variables. A significant break was found in year 1971 for the conventional EKC model, in year 1964 for 'EKC model with lnE', and in year 2001 for 'EKC model with $\operatorname{lnT}$ '. The 'EKC model with $\ln \mathrm{T}^{\prime}$ ' was also re-estimated using a $\mathrm{CO}_{2}$ measure that includes emissions from international aviation for Turkey. This additional regression (data from 1960 to 2008) recorded an $\mathrm{R}^{2}$ value of 0.87 , and produced the following elasticities: $\ln y=16.01 * ; \ln y^{2}=-1.64 * ; \ln \mathrm{T}=0.11 * *$ denotes statistical significance at the 0.05 level. 